\title{
The delayed sleep phase syndrome: clinical and investigative findings in 14 subjects
}

\author{
B Alvarez, M J Dahlitz, J Vignau, J D Parkes
}

\begin{abstract}
Fourteen subjects are described in whom a clinical diagnosis of the delayed sleep phase syndrome was made. The condition is multi-factorial, dependent on lifestyle, mood and personality, as well as on familial factors but no single factor in isolation is sufficient to explain the delay in sleep timing. Refusal to attend school may be important in some instances but will not explain cases with delayed age of onset. In half the subjects the delay in sleep phase started in childhood or adolescence. The syndrome causes severe disruption to education, work and family life. Polysomnography, motor activity monitoring of rest-activity cycles, plasma melatonin profiles and urinary melatonin metabolite excretion are normal. Different patterns of sleep phase delay seen in the syndrome include stable, progressive, irregular and non-24 hour sleep-wake cycles. These patterns may result from different social and other Zeitgebers ("time-markers", for example sunrise, sunset) in the normal environment. Treatment by forced sleepwake phase advance or with melatonin resulted in a partial sleep-phase advance but this was not maintained on stopping treatment.
\end{abstract}

$(\Im$ Neurol Neurosurg Psychiatry 1992;55:665-670)

The delayed sleep phase syndrome was first described by Weitzman et al in 1981 in a group of insomniac patients who complained of an inability to fall asleep at a socially acceptable time but were able to sleep normally at a clocktime independent of social, economic and family demands. ${ }^{1}$ The subjects comprised about $7 \%$ of the total population presenting to a Sleep Disorders Clinic with insomnia. Delayed sleep phase often began in childhood and no sex differences were found. On the owllark, "morning-evening" scale derived by Horne and Östberg, all the subjects were extreme evening types. ${ }^{2}$ Thirteen of thirty subjects had a psychiatric disorder but the distribution and nature of this was no different from other insomniacs. The syndrome did not appear to be due to school refusal or related problems, nor was it amendable by a firm discipline of enforced sleep and wake times. Almost every subject had taken many different sedative drugs and six had attempted to induce sleep by chronic night-time alcohol ingestion without success.
The existence of a specific delayed sleep phase syndrome has been questioned in the presence of the many normal environmental and social factors which disrupt the regular sleep-wake cycle. As an example of the extreme but normal range of sleep-wake pattern seen at adolescence, Wirz-Justice described the chaotic lifestyle of an undergraduate with near total loss of circadian sleep-wake rhythmicity during most of the Oxford term, who could entrain normally at exam time. ${ }^{3}$ The conclusions of Weitzman et al have been supported by other similar accounts of a delayed sleep phase syndrome, often without specific environmental or psychiatric influences. ${ }^{4-15}$ Despite these reports the definition and recognition of the delayed sleep phase syndrome has remained difficult. We report here a series of 14 subjects with a delayed sleep phase syndrome seen over a five year period in a sleep disorders clinic, presenting with a primary complaint of insomnia.

\section{Patients and methods}

SUBJECTS

The criteria for the diagnosis of delayed sleep phase syndrome were adopted from those of Weitzman et al, Thorpy, and the American Sleep Disorders Association Classification. ${ }^{1} 1617$

1) Complaint of inability to fall asleep and wake spontaneously at the desired clocktime.

2) A phase delay of the major sleep episode in relation to the desired time for sleep.

3) Symptoms present for at least 12 months.

4) No evidence of any medical, psychological, environmental or psychiatric factor sufficient to explain the above symptoms.

5) Absence of any anatomical lesion on head CT scan; and normal polysomnographic findings apart from an atypical time of sleep onset and waking.

During the period 1985-90, 14 subjects, thirteen male and one female, all of white origin, were seen and took part in a prospective study.

\section{CLINICAL EVALUATION}

All subjects had a standard clinical evaluation including sleep-logs, pubertal assessment, tests of intelligence (Mill Hill vocabulary scale and Ravens Progressive Matrices-chosen for compatability with previous studies of the delayed sleep phase syndrome); personality (Minnesota Multiphasic Personality Inventory, MMPI); mood (Beck Depression Inventory, BDI); and 
sleep-wake history (King's College Hospital sleep-wake questionnaire ${ }^{18}$ ). Twelve subjects consented to detailed investigation and had polysomnography, plasma melatonin and urinary sulphatoxy melatonin (aMT6s) profiles, head CT scan, tests of autonomic function, visual and brainstem evoked responses, and automatic recording of rest-activity cycles by actigraph.

\section{SLEEP-WAKE LOGS AND ALERTNESS SELF-RATING SCALES}

A sleep-wake subjective diary was kept over periods of four weeks to three years. Alertness was recorded on a self rating scale (drowsyalert: $0-100 \mathrm{~mm}$ ) completed at two hour intervals during wakefulness over a four week period. $^{19}$

\section{POLYSOMNOGRAPHY}

Polysomnography (first night recording) was carried out in a laboratory environment with a fixed light-dark: bed time-wake time schedule (dark, bed period 23.00-08.00). Sleep parameters and stages were determined by standard criteria using visual scoring. ${ }^{20}$

\section{REST-ACTIVITY CYCLE}

During a period of attempted phase-advance (see below), motor activity (rest-actvity cycles) were recorded by an actigraph monitor on the dominant wrist (Gähwiler Electronics, Hombrektikon, Switzerland). The actigraph was sensitive to acceleration of $0.1 \mathrm{~g}$ with preprogrammed time windows at $60 \mathrm{~s}$ intervals. Data storage of $32 \mathrm{~kb}$ was read through an IBM PC compatible interface, with a recording period of five days. Data are presented as summated text-file measures in clocktime at $15 \mathrm{~min}$ intervals.

PLASMA MELATONIN AND URINARY SULPHATOXY MELATONIN (AMT6s) CONCENTRATION

In view of the animal data indicating a central role of melatonin systems in circadian time- keeping, ${ }^{21} 22$ plasma melatonin and urinary melatonin metabolite profiles were determined. In a fixed light-dark ward environment (dark period 23.00-08.00) plasma samples for melatonin were obtained from an indwelling venus cannula at 1 hour intervals over a 24 hour period. Simultaneous urinary block collections were made between 08.00-12.00-16.00 20.00-24.00-08.00 for subsequent aMT6s analysis. Illumination levels for plasma sampling during the dark period were $<0 \cdot 1$ lux. Plasma melatonin and urinary aMT6s were assayed by radioimmunoassay ${ }^{2324}$ (plasma melatonin, $\mathrm{n}=12$; urinary aMT6s, $\mathrm{n}=11$ ).

\section{OTHER STUDIES}

In view of the association between the narcoleptic syndrome and HLA DRw15 (subtype of DR2), DQw6 (subtype of DQw1), ${ }^{25}$ and the finding of the narcoleptic syndrome in first degree relatives of index subjects with the delayed sleep phase syndrome (table 1), HLA serotyping was carried out (K Welsh, Tissue Typing Laboratory, Guy's Hospital).

\section{ATTEMPTED TREATMENT}

a) Progressive sleep phase delay schedule

Attempts were made in 5 subjects (cases 1, 3, 5,10 and 14) to achieve conventional sleepwake times by a programmed phase-delay schedule. $^{14}$

\section{b) Fixed sleep phase advance schedule}

In 9 subjects an attempt was made, using a phase-advance programme with fixed bedwake, dark-light cycle timing (bed, dark period 23.00-08.00) over a 5-day period to reschedule sleep-wake cycles to a conventional time. The effects of attempted phase-advance were monitored by self-recorded sleep-wake logs, motor activity monitors, and alertness rating scales.

c) Oral melatonin

Eight subjects were given oral melatonin $5 \mathrm{mg}$

Table 1 Clinical features of 14 cases of delayed sleep phase syndrome

\begin{tabular}{|c|c|c|c|c|c|c|c|c|c|c|c|c|c|}
\hline \multirow[b]{3}{*}{ Case } & \multirow[b]{3}{*}{ Age } & \multirow[b]{3}{*}{ Sex } & \multirow{3}{*}{$\begin{array}{l}\text { Age at } \\
\text { onset }\end{array}$} & \multirow{3}{*}{$\begin{array}{l}\text { Age onset } \\
\text { puberty }\end{array}$} & \multirow{3}{*}{$\begin{array}{l}\text { Family } \\
\text { history }\end{array}$} & \multirow{3}{*}{$\begin{array}{l}\text { Developmentall } \\
\text { environmental factors }\end{array}$} & & & \multicolumn{3}{|c|}{$\begin{array}{l}\text { Sleep-wake Parameters } \\
\text { Decimal time }\end{array}$} & \multirow{2}{*}{\multicolumn{2}{|c|}{$I Q$}} \\
\hline & & & & & & & \multicolumn{2}{|c|}{ HLA type } & \multirow{2}{*}{$\begin{array}{l}\text { Sleep } \\
\text { onset } \\
\text { mean }\end{array}$} & \multirow{2}{*}{$\begin{array}{l}\text { Wake } \\
\text { mean }\end{array}$} & \multirow{2}{*}{$\begin{array}{l}\text { Alterness } \\
\text { acrophase }\end{array}$} & & \\
\hline & & & & & & & $D R$ & $D Q$ & & & & Performance & Verbal \\
\hline 1 & 14 & $\mathbf{M}$ & 8 & 14 & a & Prolonged labour & $1, x$ & $1, x$ & 01.48 & 11.90 & 19.22 & 80 & 75 \\
\hline 2 & 39 & $\mathbf{M}$ & 33 & 14 & & $\mathrm{EBV}^{1}$ & 2,6 & $1, x$ & 07.95 & $11 \cdot 81$ & 03.43 & 125 & 103 \\
\hline 3 & 18 & $\mathbf{M}$ & 16 & 13 & b & Premature birth EBV & $3, x$ & * & $08 \cdot 10$ & $17 \cdot 15$ & $20 \cdot 19$ & 103 & 74 \\
\hline 4 & 61 & $\mathbf{M}$ & 45 & 13 & & & 4,13 & 1,3 & $04 \cdot 05$ & $15 \cdot 87$ & $04 \cdot 60$ & 126 & 92 \\
\hline 5 & 22 & $\mathbf{M}$ & 12 & 15 & & Birth hypoxia & 1,2 & 1,3 & $01 \cdot 17$ & $08 \cdot 12$ & 01.93 & 119 & 76 \\
\hline 6 & 20 & $\mathbf{M}$ & 8 & 15 & & & 2,11 & 1,3 & 02.68 & $11 \cdot 00$ & $15 \cdot 75$ & 101 & 70 \\
\hline 7 & 42 & $\mathbf{M}$ & 27 & 16 & c & & $2, x$ & $1, x$ & $03 \cdot 25$ & $10 \cdot 80$ & $20 \cdot 72$ & 108 & 93 \\
\hline 8 & 58 & $\mathbf{M}$ & 53 & 14 & & Influenza ${ }^{2}$ & 1,7 & 1,2 & $05 \cdot 30$ & $17 \cdot 30$ & $23 \cdot 50$ & 126 & 112 \\
\hline 9 & 22 & $\mathbf{M}$ & 16 & 12 & & & $1 / 10,4$ & 1,3 & $00 \cdot 22$ & $12 \cdot 00$ & $10 \cdot 18$ & NT & NT \\
\hline 10 & 14 & $\mathbf{M}$ & 10 & 11 & c & & 8,4 & $3, x$ & 03.00 & $12 \cdot 28$ & $20 \cdot 11$ & NT & NT \\
\hline 11 & 17 & $\mathbf{M}$ & 25 & 15 & & Prolonged labour & 4,6 & 1,3 & $01 \cdot 48$ & 12.04 & 13.59 & 111 & 99 \\
\hline 12 & 39 & $\mathbf{M}$ & 8 & 16 & d & & 2,3 & 1,2 & 01.55 & 08.01 & $04 \cdot 46$ & 126 & 86 \\
\hline 13 & 71 & $\mathbf{M}$ & 18 & 12 & & & 2,6 & $1, x$ & $02 \cdot 00$ & 09.00 & 23.05 & NT & NT \\
\hline 14 & 28 & $\mathrm{~F}$ & 18 & 13 & adopted & Tonic-clonic seizures, age 12 & & & 05.00 & $16 \cdot 10$ & NT & NT & 86 \\
\hline
\end{tabular}

Family history of daytime sleepiness.

b Family history of narcolepsy and cataplexy.

c Father and son.

d Father and son.

'Onset of delayed sleep phase syndrome following Epstein-Barr viral infection.

${ }^{2}$ Onset after influenza-like illness.

*Failed HLA typing.

NT not tested.

Sleep-wake parameters given in decimal time, ie $01 \cdot 30=01 \cdot 50$. Sleep-wake data derived from mean 28-day sleep logs.

Acrophase: time of subjective highest alertness self rating (computed data by cosinor analysis: from mean 28 -day self recording). 
at $22.00 \mathrm{~h}$ for a four week period double blind with matched placebo for the same period in random order with a one week washout period between the alternative treatments in their normal home environment with monitoring of sleep-wake logs and alertness rating scales. ${ }^{15}$

Comparison of sleep-wake times and alertness ratings in the normal home environment and during the forced fixed-sleep phase advance schedule, was based on within-subject differences in changes of sleep log timings and alertness self-rating scales. Comparisons were made at the end of the study by Student's $t$ test (two-tailed). Profiles of alertness rhythms, plasma melatonin and urinary aMT6s were examined for acrophase (estimated peak time) by cosinor analysis. The study was approved by the Institute of Psychiatry and King's College Hospital ethical committees. All subjects gave informed consent.

\section{Results}

The delayed sleep phase started between the ages of 8 and 53 (table 1). The onset was abrupt in 2, gradual in 12 . In four subjects the condition started before puberty (age 8-11); in four at the onset of puberty (age 12-17) and in 6 following puberty (age 18-53). In the single female subject, the syndrome started at the age of 18 (menarche at 13).

SYNDROME ANTECEDENTS

A careful review of developmental and birth history was made in view of data linking the

Figure 1 Patterns of sleep-wake disturbance $A B C$ (see text). $A=$ stable phase delay, $B=$ progressive phase delay, $C=$ irregular sleep-wake timing. acquisition of some aspects of circadian rhythmicity with foetal as well as maternal factors. $^{2627}$ In seven of 14 subjects there was a history of prolonged or difficult birth, ${ }^{4}$ delayed milestones, ${ }^{3}$ dyslexia $^{3}$ and congenital cataracts. ${ }^{1}$ Maternal health during pregnancy was described as poor by one subject, good by the remainder. Six subjects were breast-fed.

In three subjects the syndrome developed after an acute viral illness with malaise and sleepiness. All these subjects, and four others, were EBV IgG positive at the time of this study, indicating previous Epstein Barr viral infection.

FAMILY HISTORY

A family history of a sleep-wake disorder was given by six subjects (table 1 ). The father and son pair (subjects 7 and 10) lived apart from before the onset of the delayed sleep phase syndrome in the son. With the exception of these subjects, there was no report of abnormal sleep-wake timing in other first or second degree relatives of index subjects.

\section{SLEEP-WAKE TIMES}

Three different patterns of sleep-wake phase disturbance were described (fig 1).

A) Stable delay, constant over a 3-12 month period, with a sleep-wake cycle of 24 hours (10 subjects),

B) Progressive delay, with a non-24 hour sleepwake cycle of approximately 25-26 hours however, with predominant phase delay rather than advance over a three month period (1 subject)

C) Irregular sleep-wake timing with a sleepwake cycle of approximately 24 hours; however with predominant phase delay rather than advance (three subjects).

Sleep-wake times are shown in table 2. Mean sleep latency, recorded by sleep log (bed time to sleep onset time) in the home environment was a little less than 2 hours. Mean total sleep time: total wake time ratio over 24 hours was 8 hours 17 minutes: 15 hours 43 minutes (within normal values for adolescent and adult male subjects. ${ }^{28} 29$ The number of sleep periods (duration 2-18 hours) recorded by sleep $\log$ in individual subjects was between 18 and 58 ; and the number of naps (duration $<2$ hours), was between two and 56 during a 28 day period.

Despite the unusual sleep timing, 10 subjects considered that sleep duration and quality, and also waking alertness, were normal. Four subjects described a habitual poor quality of sleep, irrespective of sleep timing, and also waking fatigue, sleepiness and sub-alertness.

All subjects reported severe disability as a result of failure of morning arousal, with considerable educational, work and social problems. Education was severely disrupted in all nine subjects in whom the sleep-wake phase delay started in school years and prolonged periods of unemployment were reported in all but two adult subjects. Unhappy, unsatisfactory or unusual life styles, often with severe financial difficulties, were reported by 12 subjects, and marital problems in two of the 
Table 2 Sleep and wake times in delayed sleep phase syndrome

\begin{tabular}{lll}
\hline & Home environment & $\begin{array}{l}\text { Attempted phase advance } \\
\text { schedule with fixed } \\
\text { bed-wake time 23.00-08.00 }\end{array}$ \\
\hline Bed time (clock time) & $01 \cdot 21(2 \cdot 00)$ & $23 \cdot 00(0 \cdot 00)$ \\
Sleep onset time (clock time; sleep log) & $03 \cdot 11(0 \cdot 50)$ & $01 \cdot 14(0 \cdot 23)^{\star}$ \\
Wake time (clock time; sleep log) & $11 \cdot 28(0 \cdot 50)$ & $07 \cdot 44(0 \cdot 11)$ \\
Total sleep time (h min) & $8 \cdot 17(0 \cdot 46)$ & $6 \cdot 28(0 \cdot 28)$ \\
Alertness ratings (peak:score units) & $75(6)$ & $64(6)$ \\
Alertness rating (nadir:score units) & $49(13)$ & $17(13)^{\star}$ \\
Acrophase alertness (clock time) & $18 \cdot 50(2 \cdot 43)$ & $20 \cdot 32(1 \cdot 72)$ \\
& & Laboratory environment \\
Latency to NREM (stage II) (min) & & $89 \pm 13$ \\
Latency to REM (min) & & $116 \pm 26$ \\
Stage REM\% & 37 \\
Total sleep time (min) & & $353 \pm 43$ \\
\hline
\end{tabular}

24 hour clock times given as hours:minutes, not decimal time.

Time duration given as mins (polysomnographic data) or h.min (sleep log data)

Normal mean (SD) sleep latencies in late adolescence: first night recording.

Latency to Stage 2 NREM 31 (28) minutes.

Latency to REM 120 (52) minutes.

Total sleep time 426 (33) minutes. deviance $>2 \mathrm{SD}$ (cases two and five). One additional subject had a high depression rating on Beck Depression Inventory (score 23: case 8) and another was considered on clinical grounds to have a schizotypal personality (DSN III R) disorder although the MMPI and BDI scores were within the normal range.

Symptoms accompanying forced arousal

Six subjects reported frequent irritability, anger or dysphoria when forced arousal was attempted, and this was a conspicuous clinical feature in one adolescent male who terrified his parents on attempted morning waking. Hypersexuality was not reported or observed.

\section{Investigational findings}

Polysomnography in a fixed light-dark, bedwake time environment showed normal findings with normal sleep architecture apart from prolonged sleep latency to stage two NREM (mean 89, 1 SEM 13 minutes) and reduced total sleep time (with late sleep onset followed by forced arousal at 08.00) compared with normal values in adolescence-middle age. ${ }^{28}$ Once asleep, the latency to stage REM was within normal limits (table 2). Autonomic function tests and evoked potential studies, head CT scan, full blood count, serum biochemistry, cortisol at 09.00 and midnight and TSH were in the normal range in all subjects.

HLA serotyping (table 1) showed that 11 of 12 subjects typed were $D Q 1$ positive. The two subjects with familial DR2 (DRw15) positive narcolepsy and cataplexy were DR3,x and DR1, $x$ respectively. There were no syndromespecific HLA A, B or C associations (not included in table). Variations in HLA antigens in linkage disequilibrium with $D Q$ show that there are likely to be differences in DQ subtypes between subjects.

Plasma melatonin and urinary aMT6s excretion Plasma melatonin profile, pulse duration, peak level, and urinary aMT6s excretion over the 24 hour cycle were within the normal range for adult males aged 20-60 years living under normal light-dark environmental conditions [acrophase data (time of computed highest peak by "best-fit" curve)] for melatonin in normal subjects, summer: $03.15 \pm 01.00$ hours (mean $\pm 1 \mathrm{SD}$ ): winter $03.22 \times$ 01.34). ${ }^{30}$ There was, however, considerable variation in plasma melatonin profile in individual subjects. No significant relationships were found between melatonin onset time (first detected in plasma), peak concentration or AUC; and sleep onset time, total sleep time or alertness acrophase (all $\mathrm{p}>0 \cdot 1$ ).

\section{Attempted treatment}

A) Progressive sleep phase delay schedule Despite high motivation and parental involvement, attempted establishment of conventional sleep-wake times with a progressive 2 hour phase delay schedule twice weekly was unsuccessful in two subjects, successful in three.

B) Fixed sleep phase advance schedule

Attempts at forced sleep phase advance, with 
Sleep-wake, motor activity and melatonin cycles
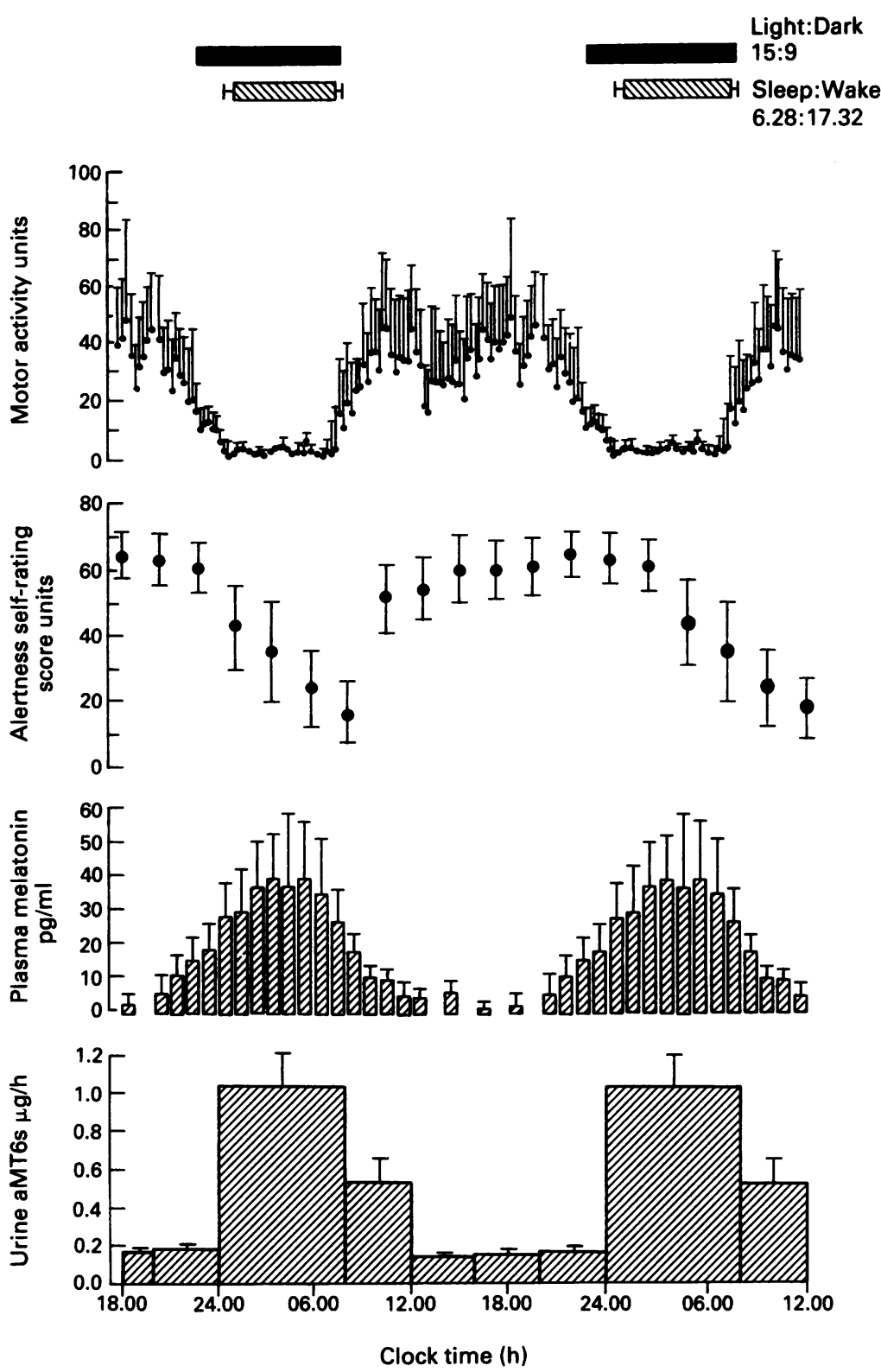

Figure 2 Motor activity, alertness ratings, plasma melatonin and urinary sulphatoxy melatonin excretion in 8 subjects with delayed sleep phase syndrome in fixed light-dark, bed-wake time (23.00-08.00 bed, dark: 08.00-23.00, wake, light) environment over five day period. During this period, the mean light:dark ratio was $15 \mathrm{~h}: 9 \mathrm{~h}$; and sleep-wake ratio $6 \mathrm{~h} 28$ min: $17 \mathrm{~h} 32 \mathrm{~min}$.

fixed bed time of 23.00 and forced arousal of 08.00 resulted in a mean 117 minute (range 7-300 minutes) advance in sleep-onset time over a five day period compared with the previous 28-day period in the home environment $(p=0.05)$. There was no significant change in sleep latency (bed time to sleep onset time) during this attempted phase-advance compared with previous 28-day period ( $p=0 \cdot 77$ : table 2). The forced arousal resulted in a reduction in total sleep time. Four subjects woke spontaneously before the 08.00 time of forced arousal. All subjects reverted to their previous sleep-wake times within 1-10 days of the attempted phase advance.

C) Melatonin treatent

Oral melatonin $5 \mathrm{mg}$ given at 22.00 caused a mean advance in sleep onset time of 82 minutes and in wake time of 117 minutes over a 28-day period compared with placebo treatment. Advance in sleep onset time with melatonin was comparable to that achieved by forced sleep-advance schedule. Neither treatment resulted in the establishment of normal sleep-wake timing. The phase shift with melatonin was independent of the time interval between the administration of exogenous melatonin and the time of the endogenous melatonin plasma peak. On stopping melatonin all subjects reverted to their previous sleep-wake times within 2-3 days. ${ }^{15}$

D) Other attempts at treatment

All subjects had made several attempts by pharmacological and non-pharmacological means to achieve conventional sleep onset and wake times. No treatment was successful in the long term with the exception of a combined benzodiazepine-amphetamine regime in case 13. Tricyclic drugs and MAO A inhibitors resulted in improvement in mood in cases 5, 8, 9 and 11 without definite alteration in sleep phase timing.

\section{Discussion}

About 75 subjects with the delayed sleep phase syndrome have been reported in the 10 years following the first description of the condition. ${ }^{1415}$ The age of onset varies from infancy to the sixth decade and is often at adolescence. Most reports have stressed male preponderance with a male:female ratio of 10:1 or higher, although the sex incidence was equal in the 30 subjects initially reported by Weitzman et al. ${ }^{1}$ The syndrome presentation is similar in children and adults. The delayed sleep phase syndrome is more common than the condition of non-24 hour sleep-wake cyclicity, or the very unusual disorder of an advanced sleep phase syndrome, characterised by habitual sleep onset and wake times that are several hours earlier than desired. ${ }^{31}$ The syndrome causes considerable disability in children and adults. In a study of 22 adolescents, Thorpy et al reported that over half the subjects had a poor school record, and 10 showed a variety of problems including irritability at school and home, and truancy. ${ }^{10}$ In adults, the work record is usually poor with many short periods of employment followed by prolonged unemployment, and often with marital and financial problems and increasing social isolation. A case has been recorded where symptoms of the delayed sleep phase syndrome were considered to be a criminal offence in military service. ${ }^{14}$ The discrepancy between verbal and performance IQ in the present subjects may have been due, at least partially, to poor school attendance.

The exact contribution of psychopathology to the syndrome is uncertain, but it seems very unlikely that in all cases, the behaviour is due to refusal to attend school, depression, boredom, laziness or personality problems, or that it could be cured, for example, by a period of military discipline. Arousal at conventional times can be impossible to achieve on a regular 
basis, or may result in severe irritability and aggression, comparable to that occurring during prolonged sleep episodes in the KleineLevin syndrome. ${ }^{32}$ No consistent psychiatric symptoms have been associated with the delayed sleep phase syndrome and reports of psychopathology in up to half of all cases may reflect an origin from psychiatric rather than medical clinics. The usual patterns of sleep duration, timing and architecture characteristic of unipolar and bipolar depression in adolescents and adults are distinct from those of the delayed sleep phase syndrome.

A variety of rhythmic and non-rhythmic sleep-wake patterns, including non-24-hour syndromes, have been reported in humans but these may only differ in degree from the delayed sleep phase syndrome. The exact pattern is perhaps determined by differences in life style and social time cues in addition to a weakened central entrainment mechanism. ${ }^{33} 34$ The 25 hour non-entrained cycle in subject 2 in this series corresponds closely to that occurring in normal subjects living in temporal isolation; similar free-running rhythms of sleep-wake may occur in congenitally blind subjects and children with mental retardation. ${ }^{3135}$ This situation is similar to that found in animal experiments, after either enucleation of both eyes or transection of the optic nerves where entrainment to the light-dark cycle is lost. $^{36}$

Patients with the delayed sleep phase syndrome are sometimes successfully treated with progressive phase delay of their sleep schedule and then maintained in a socially convenient sleep-wake time period. ${ }^{1410}$ However, results depend on motivation as well as environment. Most but not all reports stress the noneffectiveness of prolonged hypnotic treatment to promote sleep onset, or the use of morning central stimulant drugs to increase alertness. Other suggested treatments, including vitamin B12, evening alcohol, morning bright light and antidepressant drugs are not of proven efficacy. ${ }^{9-1337}$ In contrast, oral melatonin results in a partial phase advance, associated with either a hypnotic or phase-setting action. Unfortunately, the advance in sleep and wake timing is not retained on stopping treatment. $^{15}$

We thank the many people, not least our patients, who made this study possible: Professor J Arendt, Drs K Welsh, R Vaughan, G Page, V Chusney, R Elwes, H Crewes, S Folkard, $M$ Sheehy, G Robertson, J English and M Makaba for their help and Air Commodore A N Nicholson and Dr P Pascoe of the Institute of Aviation Medicine, Farnborough for their valuable assistance. J Grimshaw gave invaluable organisational support. M J D was supported by King's College Hospital and Medical Neurology Research fund and J V by Upjohn TD.

1 Weitzman ED, Czeisler CA, Coleman RM, et al. Delayed sleep phase syndrome. A chronobiological disorder with
sleep-onset insomnia. Arch Gen Psychiatry 191;38(7):737-46.

2 Horne JA, Östberg O. A self-assessment questionnaire to determine morningness-eveningness in human circadian determine morningness-eveningness in hum

3 Wirz-Justice A, Pringle C. The non-entrained life of a young gentleman at Oxford. Sleep 1987;10:57-61.

4 Czeisler CA, Richardson GS, Coleman RM, et al. Chronotherapy: resetting the circadian clock of patients with therapy: resetting the circadian clock of patients

5 Ferber R, Boyle MP. Delayed sleep phase syndrome versus motivated sleep phase delay in adolescents. Sleep Res 1983;21:239.

6 Ferber R, Boyle MP. Phase shift dyssomia in early childhood (Abst). Sleep Res 1983;12:242.

7 Wagner DR, Motira MC, Pollack CP, Czeisler CA. Entrained sleep and temperature rhythms in delayed sleep phase syndrome [abstr.]. Sleep Res 1986;15:179.

8 Pelayo RP, Thorpy MJ, Glovinsky P. Prevalence of delayed sleep phase syndrome among adolescents. Sleep Res sleep phase

9 Kamgar-Parsi B, Wehr TA, Gillin JC. Successful treatment of human non-24-hour sleep-wake syndrome. Sleep 1983;6(3):257-64.

10 Thorpy MJ, Korman E, Speilman AJ, Glovinsky PB Delayed sleep phase syndrome in adolescents. $f$ Adolesc Health Care 1988;9(1):22-7.

11 Ozaki M, Iwata T, Itoh A, Ohta T, Okada T, Kasahara Y. A treatent trial of delayed sleep phase syndrome with triazolam. If Neurology, Neurosurgery, Psychiatry 1989;43(1):51-5.

12 Ozaki N, Iwata T, Itoh A, Kogawa S, Ohta T, Okada T, Kasahara Y. Body temperature monitoring in subjects with delayed sleep phase syndrome. Neuropsychobiology with delayed sleep

13 Okawa M, Mishima K, Nanami T, et al. Vitamin B12 treatment for sleep-wake rhythm disorders. Sleep 1990;13(1):15-23.

14 deBeck TW. Delayed sleep phase syndrome-criminal offence in the military? Milit-Med 1990;155(1):14-5.

15 Dahlitz MJ, Alvarez B, Vignau J, English J, Arendt J, Parke JD. Delayed sleep phase syndrome response to melatonin Lancet 1991;i:337, 1121-4.

16 Wagner DR. Circadian rhythm sleep disorder. In: Thorpy MJ, ed. Handbook of sleep disorders. New York: Marcel Dekker, 1990:493-527.

17 ICSD-International Classification of Sleep Disorders: Diagnostic and coding manual. Diagnostic classification steering committee. Thorpy MJ, Chairman. Rochester, Minnesota: American Sleep Disorders Assaciation, 1990:1-396.

18 Shindler J, Schachter M, Brincat S, Parkes JD. Amphetamine mazindol and fencamfamin in narcolepsy. $B M^{\mathcal{F}}$ mine mazindol and

19 Folkard S, Hune KI, Minors DS, Waterhouse JM, Watson FL. Independence of the circadian rhythm in alertness
from the sleep-wake cycle. Nature 1985;313:678-9.

20 Rechtschaffen A, Kales A. A manual of standardized terminology, techniques and scoring system for sleep stages of human subjects. NIH-NINDB Bethesda Maryland NIH Publication 204, 1968

21 Krause DN, Dubocovich ML. Regulatory sites in the melatonin system of mammals. TINS 1990;13:464-70.

22 Cassone VM. Effects of melatonin on vertebrate circadian systems. TINS 1990;13:457-64.

23 Fraser S, Cowen P, Franklin M, Franey C, Arendt J. Direct radioimmunoassay for melatonin in plasma. Clin Chem 1983;29:396-7.

24 Aldhous M, Arendt J. Radioimmunoassay for 6-sulphatoxy melatonin in urine using an iodinated tracer. Ann Clin melatonin in urine using
Biochem 1988;25:293-303.

25 Honda Y, Juji T, eds. HLA and narcolepsy. Berlin: SpringerVerlag, 1988:1-208.

26 Weaver DR, Reppert SM. Maternal melatonin communicates day-length to the foetus in Djungarian hamsters. Endocrinology 1986;119:2861-3.

27 Csaba G, Nagy SU. Influence of a single neonatal melatonin treatment on the basal and thryotrophin or melatonin modified blood thyroxin level of adult rats. Acta Physio Hung 1986;68:227-9.

28 Williams RI, Karacan I, Hursch CJ. EEG of human sleep. New York: Wiley, 1974:48.

29 Carskadon MA. The second decade. In: Guilleminault C, ed. Sleeping and waking disorders. Indications and techniques. Menlo Park: Addison-Wesley, 1982:99-126.

30 Bojkowski CJ, Arendt J. Factors influencing urinary 6-sulphatoxy-melatonin, a major melatonin metabolite in normal human subjects. Clin Endocrinol normal human

31 Okawa M. Sleep-waking rhythm and its central mechanism in humans: studies of biological rhythm, computer tomography and autopsy of severely brain-damaged children. Adv Neurol 1985;29:346-65.

32 Critchley $M$. Periodic hypersomnia and megaphagia in adolescent males. Brain 1962;85:628-56.

33 Weber AL, Cary MS, Connor N, et al. Human non-24-hour sleep-wake cycles in an everyday environment. Sleep 1980;2:347-54.

34 Kamei R, Hughes L, Miles L, Dement W. Advanced sleepwake syndrome studied in a time isolation facility. Chronobiologica 1979;6:115.

35 Okawa M, Nanami T, Wade S, et al. Four congenitally blind children with circadian sleep-wake rhythm disorder. Sleep 1987;10:101-10.

36 Lincoln GA, Ebling FJP, Almedia OFX. Generation of melatonin rhythms. In: Photoperiodism, melatonin and the pineal Ciba Foundation Symposium the pineal.

37 Joseph-Van der Pool JR, Kelly KG, Schulz PM, Allen R, Souetre E, Rosenthal NE. Delayed sleep phase syndrome revisited: preliminary effects of light and triazolam. Sleep Res 1988;17:381. 